\title{
Metode K-Means dan DBSCAN pada Pengelompokan Data Dasar Kompetensi Laboratorium ITS Tahun 2017
}

\author{
Laila Qadrini \\ Universitas Sulawesi Barat \\ Jalan Prof. Dr. H. Baharuddin Lopa, S.H, Kelurahan Baurung, \\ Kecamatan Banggae Timur, Kabupaten Majene, Provinsi Sulawesi Barat 91412 \\ e-mail: laila.qadrini@unsulbar.ac.id
}

\begin{abstract}
ABSTRAK
Analisis Kelompok telah digunakan diberbagai bidang ilmu pengetahuan, dengan tujuan mengelompokkan objek/observasi. Hal penting dalam analisis kelompok adalah memperoleh nilai simpangan baku dalam kelompok yang minimum dan nilai simpangan baku antar kelompok yang maksimum, untuk memperoleh kelompok yang optimum didapatkan dengan menggunakan kriteria Elbow dan untuk menentukan validitas kelompok yaitu koefisien Silhouette dan Indeks Dunn. Pada penelitian ini dilakukan pengelompokkan variabel dasar capaian laboratorium ITS dengan menggunakan beberapa analisis kelompok, yaitu Metode K-Means, dan DBSCAN. berdasarkan hasil analisis pengelompokan diperoleh Metode DBSCAN menghasilkan nilai koefisien Silhouette dan Indeks Dunn lebih besar dibandingkan dengan Metode K-Means. Dan Jumlah dari masing-masing Metode membentuk 4 kelompok.

Kata kunci : K-Means, DBSCAN, Silhouette, Dunn, Laboratorium ITS
\end{abstract}

\section{ABSTRACT}

Clusters analysis is significantly used to classify objects/observations in various fields of science. This strategy is essentially used to obtain the minimum and maximum standard deviation values between clusters, the optimum cluster obtained using the Elbow criteria, and to determine the cluster validity, namely the Silhouette coefficient and the Dunn Index. In this study, the basic ITS laboratory performance variables were analyzed using several cluster strategies, such as the K-Means and DBSCAN methods. Based on the clustering analysis results, the DBSCAN Method produced a greater value of the Silhouette coefficient and Dunn Index than the K-Means Method. Furthermore, the sum of each method forms 4 clusters.

Keywords : K-Means, DBSCAN, Silhouette, Dunn, Laboratorium ITS

\section{PENDAHULUAN}

Analisis kelompok merupakan analisis untuk menggabungkan obyek-obyek pengamatan dalam suatu kelompok, dimana obyek dalam kelompok memiliki varians homogen namun antar kelompok memiliki varians yang heterogen. Analisis kelompok adalah Metode pengelompokan kumpulan data kedalam kelompok yang menampilkan karakteristik serupa. Pengelompokan dilakukan berdasarkan similaritas atau disimilaritas (Elvira, 2019). Hal ini berarti bahwa klaster yang baik akan mempunyai homogenitas (kesamaan) yang tinggi antar anggota dalam satu klaster (within-cluster) dan heterogenitas (perbedaan) yang tinggi antar klaster yang satu dengan yang lainnya (between-cluster).
Prosedur pengelompokan terdiri dari dua yaitu Metode hierarki dan Metode non hierarki (Musfiani, 2019). Metode hierarki digunakan jika jumlah kelompok belum ditentukan sedangkan Metode non hierarki digunakan jika jumlah kelompok telah ditentukan. Pada Metode K-Means pengelompokan data nonhierarki (partitioning) dilakukan dengan cara mempartisi data ke dalam bentuk dua kelompok atau lebih, sehingga data yang berkarakteristik sama dimasukkan ke dalam satu kelompok yang sama. Sedangkan Metode Density-Based Spatial Clustering Algorithm with Noise (DBSCAN) merupakan suatu algoritma pengelompokan yang didasarkan pada kepadatan (density) data. Setiap Metode memiliki kelebihan dan kekurangannya 
masing-masing. Hasil kelompok yang optimal dapat dipengaruhi oleh Metode pengelompokan yang digunakan, karakteristik dataset, struktur kepadatan data, ukuran data, jumlah kelompok yang digunakan. Metode Elbow digunakan untuk menentukan jumlah kelompok yang terbaik yang dapat digunakan untuk menghasilkan hasil pengelompokan yang terbaik dan dapat memaksimalkan kualitas hasil pengelompokan. (Dewa \& Dewa, 2019). Penelitian yang dilakukan Bena dkk, adalah penelitian dengan tujuan untuk melakukan pengelompokan data penjualan online retail menggunakan Metode K-Means dan DBSCAN. Percobaan dilakukan menggunakan dataset sebanyak 500 data dan memiliki 3 atribut: deskripsi, kuantitas barang per transaksi dan harga barang per unit. Hasil percobaan pada penelitian ini menunjukan, penerapan K-Means menghasilkan 3 kelompok dengan masing-masing berjumlah 103 anggota, 261 anggota dan 134 anggota. Sedangkan menggunakan DBSCAN dengan epsilon 1,005 dan minimum points 11 menghasilkan 3 kelompok dengan masing-masing berjumlah 30 anggota, 47 anggota dan 347 anggota, serta 74 data noise. (Bena et al., 2019). Penelitian yang dilakukan oleh Dewa Ayu dan Dewa Ayu membandingkan Metode Elbow dan koefisien Silhouette untuk menentukan jumlah kelompok yang tepat sehingga menghasilkan kualitas kelompok yang optimal. Metode yang digunakan untuk menguji hasil kelompok adalah Metode Davies Bouldin Index (DBI). Hasil pengujian pengelompokan dengan Metode Elbow menggunakan nilai DBI menghasilkan nilai DBI sebesar 1,10. Sedangkan pada uji coba pengelompokan dengan koefisien Silhouette menghasilkan nilai DBI sebesar 1,06. Hal ini menunjukkan bahwa hasil pengelompokan k-medoid dengan koefisien Silhouette menghasilkan kualitas kelompok lebih baik karena memiliki nilai DBI lebih rendah daripada pengelompokan kmedoid dengan Metode Elbow (Dewa \& Dewa, 2019). Selanjutnya Penelitian oleh Ninik Tri Hartanti, yaitu Penerapan algoritma K-Means untuk membentuk kelompok-kelompok siswa berdasarkan nilai rata-rata ketiga mata pelajaran UN (matematika, Bahasa Indonesia, dan Bahasa Inggris). Penentuan jumlah optimal kelompok menggunakan Metode Elbow, yang menunjukkan banyaknya kelompok optimal adalah 3, kemudian dihasilkan 3 kelompok yang terdiri dari cluster kategori "Siap", "Cukup Siap" dan Tidak Siap" (Ninik, 2020). Belum ada penelitian yang memadukan Metode K-Means dan DBSCAN dengan menggunakan Metode Elbow untuk menentukan Jumlah Kelompok yang optimal. Penelitian ini menggunakan kedua Metode tersebut karena data penelitian berukuran cukup besar dan memiliki tipe variabel kontinyu. Berdasarkan kelebihan dari Metode-Metode tersebut maka tepat digunakan untuk mencari pengelompokan terbaik pada kasus dasar Laboratorium ITS.

\section{METODE PENELITIAN}

Dalam kelompok ada banyak Metode yang bisa digunakan dan pada penelitian ini menggunakan 2 Metode yaitu sebagai berikut:

\subsection{K-Means}

K-Means merupakan Metode pengelompokan yang paling terkenal dan banyak digunakan diberbagai bidang karena sederhana, mudah diimplementasikan, memiliki kemampuan untuk mengkelompok data yang besar, mampu menangani data outlier, dan kompleksitas waktunya linear $\mathrm{O}(\mathrm{nKT})$ dengan $\mathrm{n}$ adalah jumlah dokumen, $\mathrm{K}$ adalah jumlah kelompok, dan $\mathrm{T}$ adalah jumlah iterasi. K-Means merupakan Metode pengkelompokan secara partitioning yang memisahkan data ke dalam kelompok yang berbeda. Dengan partitioning secara iteratif, K-Means mampu meminimalkan rata-rata jarak setiap data ke kelompoknya.. K-Means ditemukan oleh MacQueen pada Tahun 1967. Menurut Dean dalam Yohannes (2016) K-Means adalah salah satu teknik pengelompokkan yang paling banyak digunakan karena kesederhanaan dan kecepatan. Algoritma ini mempartisi data ke dalam $k$ kelompok dengan menetapkan setiap objek kelompok centroid terdekatnya (nilai rata- rata dari variabel untuk semua objek dalam kelompok tertentu) berdasarkan ukuran jarak yang digunakan. Hal ini lebih kuat untuk berbagai jenis variabel.

Langkah-langkah algoritma K-Means :

1. Tentukan jumlah kelompok $\mathrm{k}$

2. Pilih pusat kelompok k (pemilihan objek k dari data set dilakukan secara random) 
3. Hitung jarak setiap objek terhadap pusat kelompok.

4. Hitung kembali jarak terdekat setiap objek terhadap pusat kelompok.

5. Ulangi langkah 3 dan 4 sampai (selisih perhitungan jarak) atau iterasi maksimum tercapai.

\subsection{DBSCAN}

DBSCAN adalah algoritma pengelompokan yang didasarkan pada kepadatan (density) data (Suyanto, 2017). Konsep kepadatan yang dimaksud dalam DBSCAN adalah jumlah data yang berada dalam radius MinPts (Jumlah minimal data dalam radius $\varepsilon$ ), data tersebut masuk dalam kategori kepadatan yang diinginkan, jumlah data dalam radius tersebut termasuk data inti itu sendiri. Konsep kepadatan seperti ini melahirkan tiga macam status dari setiap data, yaitu inti (core), batas (border), dan noise. Sebuah data akan dimasukkan sebagai inti jika jumlah data tetangga dan dirinya sendiri pada radius $\varepsilon$ berjumlah $\geq$ MinPts. Nilai radius $\varepsilon$ dan MinPts ini ditetapkan secara mandiri.Untuk data yang jumlah tetangga dan dirinya sendiri dalam radius $\varepsilon$ kurang dari MinPts, tetapi tetangganya menjadi inti karena kehadirannya, data tersebut dikategorikan sebagai batas.Jika jumlah tetangga dan dirinya sendiri dalam radius $\varepsilon$ kurang dari MinPts dan tidak ada tetangga yang menjadi inti karena kehadirannya, data tersebut dikategorikan sebagai noise (Diah et al., 2017). Mendefinisikan kelompok sebagai satu set poin dengan kepadatan maksimal yang terhubung. DBSCAN menentukan sendiri jumlah kelompok yang akan dihasilkan, tapi memerlukan 2 input lain, yaitu:

1. MinPts : minimal banyak items dalam suatu kelompok

2. Eps : nilai untuk jarak antar-items yang menjadi dasar

pembentukan neighborhood dari suatu titik item.

Beberapa istilah mengenai DBSCAN:

1. Lingkungan dalam radius Eps suatu objek tertentu disebut objek e-neighboorhood.

2. Jika e-neighboorhood dari sebuah objek berisi setidaknya jumlah minimal, MinPts, objek, maka objek disebut objek inti (core object).

3. Ada 2 jenis titik (points) dalam suatu kelompok: titik tengah di dalam kelompok (core points) dan di tepian kelompok (border points).

4. Neighborhood dari border points berisi jauh lebih sedikit items daripada neighborhood dari core points. Suatu border point bisa jadi termasuk ke dalam lebih dari 1 core object. (Qadrini, 2020).

\subsection{Metode Elbow}

Metode Elbow merupakan salah satu Metode untuk menentukan jumlah kelompok yang tepat melalui persentase hasil perbandingan antara jumlah kelompok yang akan membentuk siku pada suatu titik (Dewa \& Dewa, 2019). Jika nilai kelompok pertama dengan nilai kelompok kedua memberikan sudut dalam grafik atau nilainya mengalami penurunan paling besar maka jumlah nilai kelompok tersebut yang tepat. Untuk mendapatkan perbandingannya adalah dengan menghitung Sum of Square Error (SSE) dari masing-masing nilai kelompok. Karena semakin besar jumlah nilai kelompok k, maka nilai SSE akan semakin kecil. Rumus SSE sesuai dengan Persamaan 1.

$S S E=\sum_{k=1}^{k} \sum_{x_{i}}\left[x_{i}-c_{k}\right]^{2}$

$\mathrm{k} \quad:$ Kelompok ke-c

$x_{i}$ : Jarak data objek ke- $i$

$c_{k} \quad$ : Pusat kelompok ke- $i$

\subsection{Validitas Kelompok}

Validasi kelompok adalah prosedur yang mengevaluasi hasil analisis kelompok secara kuantitatif dan objektif. Terdapat tiga pendekatan untuk mengeksplorasi validitas kelompok yaitu validasi eksternal, internal dan relatif. Dalam penelitian ini akan digunakan validasi internal, yaitu dengan menggunakan Metode Silhouette dan Indeks Dunn (Jain \& Dubes, 1988).

\subsubsection{Indeks Dunn}

Indeks Dunn adalah rasio jarak terkecil antara observasi pada kelompok yang berbeda dengan jarak terbesar pada masing-masing cluster data. Indeks Dunn diperoleh dari hasil pembagian antara $d_{\text {min }}$ dengan $d_{\text {max }}$.

$C=\frac{d_{\min }}{d_{\max }}$

$d_{\text {min }}$ : Jarak terkecil antara observasi pada kelompok yang berbeda 
$d_{\text {max }}$ : Jarak terbesar pada masing-masing kelompok data

Nilai DI yang semakin besar menandakan hasil pengelompokan yang semakin baik. (Nurul \& Edy,2017).

\subsubsection{Indeks Silhouette}

Indeks Silhouette merupakan gabungan dari Metode separasi dan kohesi. (Kodinariva \& Makwana, 2013). Untuk menghitung nilai silhoutte coefisient diperlukan jarak antar objek dengan menggunakan rumus Euclidean Distance. Setelah itu tahapan untuk menghitung nilai Silhoutte Coeffisient adalah sebagai berikut :

1. Untuk setiap objek $i$, hitung rata-rata jarak dari objek $I$ dengan seluruh objek yang berada dalam satu kelompok. Akan didapatkan nilai rata-rata yang disebut $a_{i}$.

2. Untuk setiap objek $i$, hitung rata-rata jarak dari objek $i$ dengan objek yang berada di kelompok lainnya. Dari semua jarak rata-rata tersebut ambil nilai yang paling kecil. Nilai ini disebut $b_{i}$.

3. Setelah itu maka untuk objek $i$ memiliki nilai Silhouette Coeffisient:

$S_{i}=\frac{\left(b_{i}-a_{i}\right)}{\max \left(a_{i}, b_{i}\right)}$

hasil perhitungan nilai Silhoutte Coeffisient dapat bervariasi antara -1 hingga 1. Hasil pengelompokan dikatakan baik jika nilai Silhoutte Coeffisient bernilai positif $\left(a_{i}<b_{i}\right)$ dan $a_{i}$ mendekati 0 , sehingga akan menghasilkan nilai Silhoutte Coeffisient yang maksimum yaitu 1 saat $a_{i}=0$. Maka dapat dikatakan, jika $S_{i}=1$ berarti objek $i$ sudah berada dalam kelompok yang tepat. Jika nilai $S_{i}=0$ maka objek $i$ berada di antara dua kelompok sehingga objek tersebut tidak jelas harus dimasukan ke dalam kelompok $\mathrm{A}$ atau kelompok B. Akan tetapi, jika $S_{i}=-1$ artinya struktur kelompok yang dihasilkan overlapping, sehingga objek $i$ lebih tepat dimasukan ke dalam kelompok yang lain. Nilai rata-rata Silhouette Coeffisient dari tiap objek dalam suatu kelompok adalah suatu ukuran yang menunjukan seberapa ketat data dikelompokan dalam kelompok tersebut. Berikut adalah nilai Silhouette Coefficient berdasarkan (Kaufman \& Rousseeuw, 1990) adalah:

Laila Qadrini / J Statistika Vol. 13, No. 2, (2020)
Tabel 1. Nilai Coeffisien Silhouette

\begin{tabular}{cl}
\hline \multicolumn{1}{c}{ Nilai SC } & Keterangan \\
\hline $0,7<S C \leq 1$ & Struktur Kuat \\
$0,5<S C \leq 0,7$ & Struktur Medium \\
$0,25<S C \leq 0,5$ & Struktur Lemah \\
$S C \leq 0,25$ & Tidak ada Struktur \\
\hline
\end{tabular}

\subsection{Teknik Pengolahan Data}

Teknik pengolahan data dalam penelitian ini adalah pengelompokan dengan Metode KMeans dan Metode DBSCAN menggunakan software R Statistic 3.6.3. Tahap analisis data yang digunakan dalam penelitian ini sebagai berikut :

1.Melakukan preprocessing data

2.Menentukan Jumlah Kelompok yang optimal

3.Melakukan pengelompokan data menggunakan Metode K-Means

4.Melakukan pengelompokan data menggunakan Metode DBSCAN

5. Pengujian validitas kelompok menggunakan uji Koefisien silhouette dan Indeks Dunn pada kelompok yang telah dibentuk menggunakan Metode K-Means dan DBSCAN

\section{HASIL DAN PEMBAHASAN 3.1 Sumber Data}

Sumber data yang digunakan merupakan data Dasar Capaian Laboratorium Semester 1 Institiut Teknologi Sepuluh Nopember Surabaya Tahun 2017. Data yang digunakan adalah Laboratorium Dasar FTSP, FTIF, FBMT, Vokasi, dan FTI. Metode yang digunakan dalam penelitian ini adalah metode pengelompokan K-Means, dan DBSCAN. Untuk kriteria kebaikan pengelompokan yang diterapkan adalah Silhouette Coefficient. Adapun persamaan untuk menghitung kebaikan model tersebut adalah sebagai berikut:

$a(0)=\frac{\sum_{o^{\prime} \in C_{i}, o \neq o^{\prime}} \operatorname{dist}\left(o, o^{\prime}\right)}{\left|C_{i}\right|-1}$

Dan

$b(0)=\min _{C_{j: 1 \leq j \leq k, j \neq 1}} \frac{\sum_{o^{\prime} \in C_{i}, o \neq o^{\prime}} \operatorname{dist}\left(o, o^{\prime}\right)}{\left|C_{i}\right|}(5)$ 
Untuk mengukur kualitas kelompok dalam suatu pengelompokan, kita dapat menghitung rata-rata Silhouette Coefficient dari semua objek dalam kelompok tersebut. Sementara itu, untuk mengukur kualitas suatu pengelompokan, kita dapat menggunakan ratarata silhouette coefficient dari semua objek dalam kelompok.

$s(0)=\frac{b(o)-a(o)}{\max \{a(o), b(o)\}}$

\subsection{Analisis Deskriptif}

Ada beberapa Metode yang digunakan pada penelitian ini, tetapi sebelum membahas Metode yang digunakan terlebih dahulu akan diteliti untuk karakteristik data yang digunakan dalam penelitian ini menggunakan analisis deskriptif. Penjelasan tentang karakteristik data pada penelitian ini dapat dilihat pada tabel berikut ini

\begin{tabular}{lr|r|r|r|r|}
\multicolumn{7}{c}{ Tabel 2. Descriptive Statistics } \\
& & & & & \multicolumn{1}{c|}{$\begin{array}{c}\text { Std. } \\
\end{array}$} \\
& N & Min & Max & Mean & Deviation \\
\hline X1 & 93 & 0 & 33 & 7.05 & 7.030 \\
\hline X2 & 93 & 0 & 14 & 4.75 & 3.031 \\
\hline X3 & 93 & 0 & 11 & 3.46 & 2.362 \\
\hline X4 & 93 & 0 & 7 & .61 & 1.344 \\
\hline X5 & 93 & 0 & 9 & 1.04 & 1.841 \\
\hline X6 & 93 & 0 & 29 & 2.13 & 3.987 \\
\hline X7 & 93 & 0 & 11 & 1.18 & 2.131 \\
\hline X8 & 93 & 0 & 1569 & 297.91 & 378.832 \\
\hline X9 & 93 & 0 & 7 & .70 & 1.397 \\
\hline X10 & 93 & 0 & 30 & 2.38 & 4.046 \\
\hline X11 & 93 & 0 & 55 & 4.34 & 8.513 \\
\hline
\end{tabular}

Jumlah data yang diteliti sebanyak 94 (Lab) dengan nilai terkecil adalah 0 terdapat pada beberapa variabel yang menjelaskan bahwa pada setiap Lab mempunyai penelitian yang tidak dipublikasikan. Nilai maksimum dan ratarata terbesar terdapat pada variabel X8 (Jumlah Sitasi Dosen dalam Google Scholar) sebesar 1569 pada Logistics and Supply Chain

Laila Qadrini / J Statistika Vol. 13, No. 2, (2020)
Management Lab. dan rata-rata sebesar 297,91 dan nilai standar deviasi sebesar 378,832.

\subsection{Menentukan Jumlah Kelompok yang Optimal}

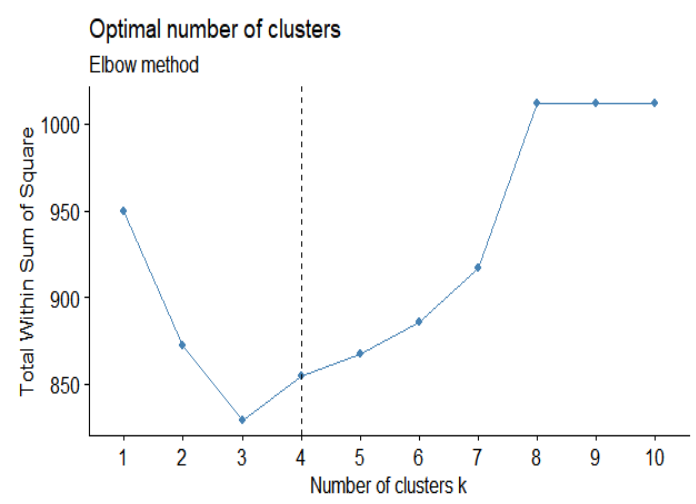

Gambar 1. Jumlah Kelompok Optimal

Berdasarkan Gambar 1 sesuai output pada Software R 3.5.5, diperoleh keterangan sesuai hasil analisis Metode Elbow untuk pengelompokan K-Means dan DBSCAN, jumlah kelompok optimal untuk mengelompokkan kompetensi laboratorium ini adalah 4 kelompok

\subsection{Metode Pengelompokan Terbaik 3.4.1 Hasil Pengelompokan K-Means}

Berdasarkan hasil analisis dari metode Elbow, diperoleh bahwa jumlah kelompok yang terbentuk adalah 4 dengan nilai Average Silhouette sebesar 0,4 , sesuai Tabel 1 nilai Silhouette Coefficient $\leq 0,5$ yang berarti termasuk struktur lemah, atau objek-objek pada penelitian ini yaitu dasar capaian kompetensi Laboratorium belum berada pada kelompok yang tepat, hal ini mengindikasikan bahwa Metode K-Means kurang tepat diterapkan pada penelitian ini. Adapun plot dari silhouette untuk K-Means adalah dibawah ini :

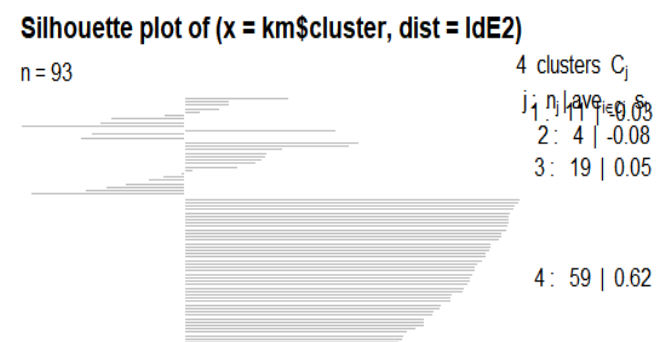


nilai coeffient silhouette terbesar dan nilai Indeks Dunn yang mana lebih besar daripada nilai koefisien Silhouette dan Indeks Dunn Metode K-Means. Hal ini mengidentifikasikan bahwa kelompok berdasarkan kepadatan objek yang diamati.

Tabel 3. Perbandingan Indeks Silhouette dan

Gambar 2. Plot Silhouette K-Means

\subsection{Hasil Pengelompokan DBSCAN}

Berdasarkan hasil analisis dari metode Elbow diperoleh bahwa jumlah kelompok yang terbentuk adalah 4 dengan nilai Average silhouette sebesar 0,72 yang berarti termasuk struktur kuat, menurut (Kaufman dan Rousseeuw, 1990) nilai Average silhouette yang mendekati 1 menunjukkan hasil pengelompokan yang baik. Atau objek-objek yang pada penelitian ini adalah dasar capaian kompetensi Laboratorium telah berada pada kelompok yang tepat. Sehingga metode DBSCAN lebih tepat diterapkan dibandingkan metode K-Means, adapun plot dari silhouette DBSCAN adalah dibawah ini :

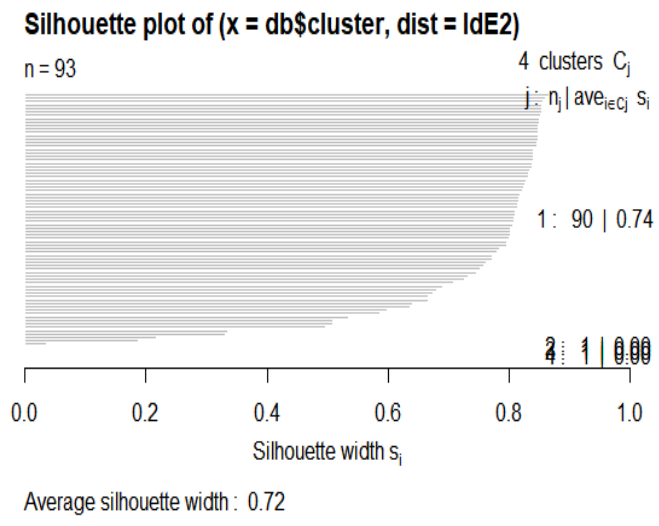

Gambar 3. Plot Silhouette DBSCAN

Berdasarkan Tabel 3 dapat diketahui Metode kelompok terbaik pada data Dasar Capaian Laboratorium Semester I Institut Teknologi Sepuluh Nopember Surabaya Tahun 2017 menggunakan Metode DBSCAN berdasarkan

\begin{tabular}{ccc}
\multicolumn{2}{c}{ Indeks Dunn } \\
\hline Metode & $\begin{array}{c}\text { Indeks } \\
\text { Silhouette }\end{array}$ & $\begin{array}{c}\text { Indeks } \\
\text { Dunn }\end{array}$ \\
\hline K-Means & 0,40 & 0,12 \\
DBSCAN & 0.72 & 0,57 \\
\hline
\end{tabular}

\section{KESIMPULAN}

Berdasarkan analisis data dan pembahasan tentang Dasar Capaian Laboratorium Semester I Institut Teknologi Sepuluh Nopember Surabaya Tahun 2017, dapat diambil kesimpulan sebagai berikut:

1. Hasil analisis Metode Elbow untuk pengelompokan K-Means dan DBSCAN menghasilkan jumlah kelompok yang optimal adalah 4 kelompok

2. Metode Pengelompokan terbaik adalah Metode DBSCAN dengan nilai Silhouette Coeffient sebesar 0,72 dengan eps $=5.5$ dan Minpts $=1$.

\section{DAFTAR PUSTAKA}

Ashari, S. B., Otniel, C. S., \& Rianto. 2019. Perbandingan Kinerja K-Means dengan DBSCAN untuk Metode Clustering Data Penjualan Online Retail. Jurnal Siliwangi Vol.5. No.2.

Dewi A.I.C.D., \& Pramita A.K.D. 2019. Analisis Perbandingan Metode Elbow dan Sillhouette pada Algoritma Clustering K-Medoids dalam Pengelompokan Produksi Kerajinan Bali (Jurnal Matrix), Vol. 9, No. 3, November 2019. 
J Statistika Vol. 13, No. 2, (2020), Hal. 5-11

Halim N. N., \& Widodo, E. 2017. Clustering Dampak Gempa Bumi di Indonesia Menggunakan Kohonen Self Organizing Maps, Prosiding SI MaNIs (Seminar Nasional Integrasi Matematika dan Nilai Islami) Vol.1, No.1, pp 188-194.

Hartanti, T. N. 2020. Metode Elbow dan KMeans Guna Mengukur Kesiapan Siswa SMK Dalam Ujian. Jurnal Nasional Teknologi dan Sistem Informasi. Vol. 06 N0. 02. pp 82-89.

Hermanto, P.M., Elvira, 2019. Pengelompokan Kabupaten Kota Di Provinsi Jawa Timur Berdasarkan Indikator Kesehatan Mortalitas Dengan Algoritma Variable Weighting $K$ Means. J Statistika, Vol 12, No. 1, pp 20-25.

Jain, \& Dubes. 1988. Algorithm for Clustering Data.https://homepages.inf.ed.ac.uk/rbf /BOOKS/JAIN/Clustering Jain Dubes. pdf, diakses tanggal 27 November 2020.

Kaufman, L., \& Rousseuw, P.J. 1990. Finding Groups in Data: An Introduction to Cluster Analysis. New York. Wiley.

Musfiani. 2019. Analisis Cluster Dengan Menggunakan Metode Partisi Pada Pengguna Alat Kontrasepsi Di Kalimantan Barat. Buletin Ilmiah Math. Stat. dan Terapannya (Bimaster). Vol 8. No. 4. pp 893-902.

Safitri, D., Wuryandari, T., \& Rahmawati, R. 2017. Metode DBSCAN untuk Pengelompokan Kabupaten/Kota Di Provinsi Jawa Tengah Berdasarkan Produksi Padi Sawah Dan Padi Ladang. Statistika, Vol. 5, No. 1.

Suyanto. 2017. Data Mining Untuk Klasifikasi www.unipasby.ac.id

dan Klasterisasi Data. Bandung: Informatika Bandung

T. M. Kodinariya, \& P. R. Makwana, 2013.

Review on determining number of cluster in K-Means Clustering, Int. J. Adv. Res. Comput. Sci. Manag. Stud. Vol. 1. No. 6.

Yohannes. 2016. Analisis Perbandingan Algoritma Fuzzy C-Means dan $K$ Means. Prosiding Annual Research. Vol 2. No. 1.

Qadrini, L. (2020). Ensembel Fuzzy, Ensembel Rock Pada Pengelompokan Pelamar Bidikmisi Sejawa Timur Tahun 2017. Jurnal MSA (Matematika Dan Statistika Serta Aplikasinya), 8(1), 4650. http://journal.uinalauddin.ac.id/index.php/msa/article/vie w/JMSA.VOL8N1046/pdf 